\title{
Exploring the Role of the Workplace in Experiences of Commuter Stress: A Mixed-Method Study from Sofia, Bulgaria
}

\author{
Anna Plyushteva
}

Citation: Plyushteva, Anna. 2021. Exploring the Role of the Workplace in Experiences of Commuter Stress: A Mixed-Method Study from Sofia, Bulgaria. Social Sciences 10: 208. https://doi.org/10.3390/socsci10060208

Academic Editor: Andrew Barnfield

Received: 14 May 2021

Accepted: 31 May 2021

Published: 1 June 2021

Publisher's Note: MDPI stays neutral with regard to jurisdictional claims in published maps and institutional affiliations.

Copyright: (C) 2021 by the author. Licensee MDPI, Basel, Switzerland. This article is an open access article distributed under the terms and conditions of the Creative Commons Attribution (CC BY) license (https:// creativecommons.org/licenses/by/ $4.0 /)$.
Transport Studies Unit, School of Geography \& The Environment, University of Oxford, Oxford OX1 2JD, UK; anna.plyushteva@ouce.ox.ac.uk

\begin{abstract}
Several studies have argued that the effects of commuter stress spill into other domains of everyday life, including the workplace. However, the entanglements between commuter stress and the workplace are complex and multidirectional. Commuter stresses both shapes and is shaped by managerial policies, workplace social relations, and the negotiations of working schedules. The present paper explores these interconnections. Drawing on a survey of 281 office-based employees in 27 companies in Sofia, Bulgaria, the paper demonstrates how the characteristics of individuals and individual journeys are important in shaping commuter stress but not exclusively so. In examining the significance of the workplace in relation to commuter stress, the paper differentiates between the geographical location of the workplace and the employing organisation, thus offering a granular understanding of spatial (e.g., the quality of the public spaces surrounding the office) and organisational (e.g., managerial decisions regarding parking) factors. The paper highlights the social and spatial constraints within which commutes are carried out, thus emphasising the role of employers and local government in what is often understood in terms of individual travel choices.
\end{abstract}

Keywords: commuter stress; Sofia; mobility; workplace; mobility planning

\section{Introduction}

Commuter stress is a significant concern from both a public health and a sustainable mobility perspective (Legrain et al. 2015). In the present paper, I explore how individual commuter stress is shaped by characteristics of a particular type of community-the workplace. Despite calls to consider the broader spatial and social relations within which everyday mobility is situated, research on everyday mobility in general and the commute, in particular, continues to focus almost exclusively on the individual (cf. Manderscheid 2013; Bissell 2010). The present paper focuses on the workplace as one of the sites of collective life in which commuter stress is lived and manifested (other obvious ones being home life and urban public space). The wider context of this study is the growing body of work at the intersection between transport/mobility and well-being research. Within this burgeoning interdisciplinary field, there is growing recognition of the need to engage with both community and individual framings of the mutual shaping of everyday mobility and well-being (De Vos et al. 2013).

The definition of commuter stress explored here has multiple dimensions. The paper focuses on stressful relations which are linked to, yet exceed, both the psychophysiological state of the individual commuter and the spatial-temporal 'container' of the commuter's journey. Stress is examined in its wider social and spatial context, focusing in particular on the workplace. The mixed-method approach taken reflects this conceptualisation of commuter stress as both quantifiable and lived through a range of social and spatial relations.

\section{The Stressful Commute}

In transport and mobility research, the stressfulness of a journey is often understood as one dimension connecting mobility and well-being, alongside traffic safety, air pollution, 
noise, opportunity to engage in meaningful activity, and physical activity (Chatterjee et al. 2017; Singleton et al. 2020). The main focus in this body of research has been on identifying the causes of commuter stress, with particular focus on the characteristics of the journey and the travelling individual (also referred to as objective/environmental stressors, and subjective experience, Legrain et al. 2015). In practice, the interactions between the individual and their environment can be difficult to disentangle into clear-cut components of stress. Among all others, the link that has attracted the most attention, and which has received the most empirical backing across different contexts, is the effect of different transport modes on levels of commuter stress. Driving has been consistently found to be more stressful than other modes, even when associated with greater comfort (Gatersleben and Uzzell 2007; LaJeunesse and Rodríguez 2012). Additional aspects of the commute which determine levels of stress include duration, predictability, and perceived control over the journey (Sposato et al. 2012; Chatterjee et al. 2017; Morris and Guerra 2015; Wener and Evans 2011).

\section{Commuter Stress and the Workplace}

While a number of studies in transport and mobilities research have begun to challenge the view of the mobile subject as a solitary, bounded entity driven by rational utilitymaximising behaviour, relational thinking has not generally been applied to the study of commuter stress. Overall, commuter stress continues to be understood as a matter of accumulation that is experienced and thus knowable at the level of the individual (Bissell 2014; Ettema 2010). While the impact of commuter stress on women has been examined to an extent from the perspective of feminist geography, such research has focused predominantly on women juggling employment, household and care work as part of their everyday mobility (Gilow 2020; Schwanen and de Jong 2008). To the extent that the link between commuter stress and workplaces has been examined in previous literature, studies have mostly focused on understanding the effects of stress on work performance. A few publications have identified varying degrees of association between commuter stress levels and job satisfaction, absenteeism, and workplace aggression (Koslowsky et al. 1995; Wener and Evans 2004; Chatterjee et al. 2017; Hennessy 2008). A 2006 review by Cox, Houdmont, and Griffiths identified studies that have aimed to quantify the loss of productivity associated with the stress resulting from commuting on crowded trains in the UK (Cox et al. 2006).

Beyond these studies, an even more limited number of publications have examined the reverse relationship, i.e., the impact of the workplace on the experience of commuter stress. A 2011 study by Abou-Zeid and Ben-Akiva examined the role of social interactions in commuter well-being, showing how comparisons with others' commutes modulate commuters' evaluation of their own experiences (Abou-Zeid and Ben-Akiva 2011). Plyushteva (2019b) has discussed how commuter stress is brought into the workplace but is also defused in it, as co-workers share stories of stressful journeys and plan for mitigating their negative effects. The present paper extends this body of research by exploring how the spatial and organisational characteristics of a workplace shape the experience of commuter stress.

\section{Transport and Mobility in Sofia}

In 2017, the city of Sofia, the capital of Bulgaria, had a population of approximately 1.3 million (National Statistics Institute 2018). Sofia has an extensive public transport network, which had reached impressive coverage during state Socialism (1944-1989) but fell into increasing disrepair from the 1970s onwards, as a result of declining government funding and the rise of private car use (Plyushteva 2019a). The decline of public transport has been addressed to an extent since the early 2000s, through the renewal of rolling stock, building a metro network, an overall boost in funding, and a growing political focus on air quality and traffic congestion. Nevertheless, the problems associated with car dominance remain acute (Barnfield 2017). They have been exacerbated through the addition of more and more residential and office developments along the city limits, often without 
adequate infrastructure for cycling and walking, nor sufficient public transport services (Stanilov and Hirt 2014). While commuter stress is unlikely in itself to be the cause of the modal shift, because of the range of constraints commuters experience, understanding it is key to planning context-appropriate interventions for improving urban mobility.

\section{Materials and Methods}

This paper draws on data collected as part of a mixed-method research project conducted in 2017-2019, which focused on the role of employers in the promotion of sustainable and affordable commutes. The data reported here were collected in collaboration with Sofia Municipality, with a survey on commuting distributed among the office-based employees of 27 companies. The survey questionnaire featured 84 questions of different types, including multiple open-ended questions. These questions encouraged respondents to describe aspects of their commute in their own words, e.g., problems they encounter, what they would like the local authority to do to improve transport and mobility, and their ideal commute. 286 completed questionnaires were returned, of which 281 are the basis of the present paper, having no missing answers to questions related to commuter stress. Data analysis included two stages, covering individual and community-level data, where the community is defined as the workplace in its social and spatial dimensions. In the first stage, quantitative analysis was conducted, focusing on variables related to commuter stress and to specific causes and impacts of commuter stress. The key dependent variable this analysis focused on was a 5-point Likert scale questionnaire item inviting respondents to indicate the level of stress they associated with their commute on a typical day (ranging from $1=$ not stressful to $5=$ very stressful). This part of the data analysis relied on exploratory correlations to map out the factors pertaining to individual commuters and their journeys which could be linked to higher levels of commuter stress. In the second stage of data analysis, Kruskal-Wallis tests were carried out to analyse the variance in commuter stress between employing organisations and between different locations. Finally, both qualitative and quantitative data were examined at the level of each of the workplaces studied. Narrative responses were coded and analysed thematically. The preliminary exploration of the data was used to build an ordinal logistic regression model to examine the significance of organizational factors to the experience of commuter stress. Variables that were found not to be significant were excluded from the model. Where specific responses and/or companies have been mentioned, data have been pseudonymized so that individuals and companies cannot be identified from the reported findings.

\section{Findings}

\subsection{Individual Commuter Stress}

This first section presents initial insights into the characteristics of individual commuters and their journeys and the extent to which they were likely to be associated with commuter stress. Following this, the rest of the analysis aims to add nuance and complexity to observations on individuals' transport mode, journey duration, and demographic characteristics, by examining the organisational characteristics of their workplace. Both sets of variables are then integrated into an ordinal logistic regression and the results are discussed.

As part of the survey, respondents were asked to indicate all transport modes they were likely to use as part of their typical commute. Although the share of respondents who indicated the private car as a typical commuting mode was the highest, at $54 \%$, the share of respondents regularly using public transport was also above $50 \%$, and over $19 \%$ of respondents indicated that they typically walked to work. These findings reflect the particularities of Sofia's spatial form and development as a relatively dense, multimodal, and mixed-use city (Stanilov and Hirt 2014; Hirt 2007). The share of respondents reporting cycling to work, at $10 \%$, was high compared to city-level statistics on the modal share of cycling (1.8\% in 2017; Vision for Sofia 2018). This reflected the over-representation in the sample of younger people, white-collar workers, and men. Notably, $33 \%$ of respondents 
indicated more than one transport mode in describing their commute. The most commonly reported multimodal commute was one combining public transport and walking, although cycling was also correlated with using more than one mode of transport to travel to work. In the case of drivers, therefore, the influence of the private car mode in shaping commuter stress is likely to be stronger, whereas, for other modes, the link to stress is more diffuse, and likely also connected specifically to the multimodal nature of journeys, i.e., the need to transfer between modes (see Table 1).

Table 1. (a) Transport modes used to travel to work on a typical day. Multiple answers are possible. (b) Pearson correlation results, using a particular transport mode associated with using multiple modes.

(a)

\begin{tabular}{|c|c|c|c|c|c|}
\hline & Percent & & & & \\
\hline $\begin{array}{c}\text { Private car } \\
\text { (driver or passenger) }\end{array}$ & 54.4 & & & & \\
\hline $\begin{array}{l}\text { Public transport (incl. metro, } \\
\text { tram, trolleybus, bus) }\end{array}$ & 50.2 & & & & \\
\hline On foot & 19.2 & & & & \\
\hline Bicycle & 10 & & & & \\
\hline Taxi & 9.6 & & & & \\
\hline Other & 1.8 & & & & \\
\hline \multirow[t]{2}{*}{ Marshrutka (minibus) } & 0.4 & & & & \\
\hline & Percent & & & & \\
\hline Car (driver or passenger) & 54.4 & & & & \\
\hline $\begin{array}{l}\text { Public transport (incl. metro, } \\
\text { tram, trolleybus, bus) }\end{array}$ & 50.2 & & & & \\
\hline On foot & 19.2 & & & & \\
\hline Bicycle & 10 & & & & \\
\hline Taxi & 9.6 & & & & \\
\hline Other & 1.8 & & & & \\
\hline \multirow[t]{3}{*}{ Marshrutka (minibus) } & 0.4 & & & & \\
\hline & & $(\boldsymbol{b})$ & & & \\
\hline & Multiple Modes & Private Car & Public Transport & On Foot & By Bicycle \\
\hline Multiple modes & - & 0.09 & $0.331 *$ & $0.410 *$ & $0.350 *$ \\
\hline Private car & 0.09 & - & $-0.640 *$ & $-0.225^{*}$ & 0.018 \\
\hline Public transport & 0.331 * & $-0.640 *$ & - & 0.016 & 0.022 \\
\hline On foot & $0.410 *$ & $-0.225^{*}$ & 0.016 & - & $0.139 *$ \\
\hline Bicycle & 0.350 * & 0.018 & 0.022 & $0.139 *$ & - \\
\hline
\end{tabular}

Overall, $64 \%$ of respondents described their commute as either 'quite stressful' or 'very stressful.' In contrast to previous studies, the impact of mode on the stressfulness of the commute was not clear-cut. An exploratory correlation indicated that public transport and multimodal commutes were associated with higher levels of commuter stress, whereas pedestrian commutes implied lower levels of stress. However, driving was not found to be correlated with either heightened or reduced levels of stress (Table 2). Once again, the level of ambiguity in the identified relationships between commuter stress and transport mode reflected the purposeful aim of the survey to make visible multimodal commutes. As the questionnaire did not require respondents to choose one 'main' mode, but highlighted all modes they regularly used, the key finding here is the correlation between stressfulness and multimodal commutes. 
Table 2. Exploratory correlations on reported levels of commuter stress.

\begin{tabular}{|c|c|c|c|c|c|c|c|c|c|c|c|c|}
\hline & \multicolumn{12}{|c|}{ Transport Mode } \\
\hline & $\begin{array}{c}\text { Level of } \\
\text { Commuter Stress } \\
\text { (Likert 1-5) }\end{array}$ & $\begin{array}{l}\text { Distance } \\
\text { Home- } \\
\text { Workplace }\end{array}$ & $\begin{array}{c}\text { Trip } \\
\text { Duration }\end{array}$ & $\begin{array}{l}\text { Multi- } \\
\text { Modal } \\
\text { Commute }\end{array}$ & $\begin{array}{l}\text { Private } \\
\text { Car }\end{array}$ & $\begin{array}{l}\text { Public } \\
\text { Transport }\end{array}$ & On Foot & Bicycle & Income & Age & $\begin{array}{c}\text { Gender } \\
\text { (Reference Is } \\
\text { Female) }\end{array}$ & Children \\
\hline $\begin{array}{l}\text { Distance between } \\
\text { home and } \\
\text { workplace }\end{array}$ & 0.314 * & - & $0.564 *$ & -0.095 & 0.046 & $0.159 *$ & -0.394 * & -0.124 * & -0.089 & -0.052 & 0.016 & 0.030 \\
\hline $\begin{array}{l}\text { Multimodal } \\
\text { commute }\end{array}$ & $0.118^{*}$ & -0.095 & 0.084 & - & 0.090 & 0.331 * & $0.410 *$ & $0.350 *$ & 0.108 & -0.027 & 0.039 & -0.021 \\
\hline Private car & 0.117 & 0.046 & $-0.377^{*}$ & 0.090 & - & $-0.640 *$ & $-0.225 *$ & 0.018 & $0.172 *$ & 0.032 & $0.134 *$ & 0.096 \\
\hline Public transport & $0.137^{*}$ & $0.159 *$ & $0.536^{*}$ & 0.331 * & -0.640 * & - & 0.016 & 0.023 & -0.154 * & -0.054 & $-0.165 *$ & -0.068 \\
\hline On foot & -0.208 * & $-0.394 *$ & -0.108 & $0.410 *$ & $-0.225 *$ & 0.016 & - & $0.139 *$ & 0.041 & -0.058 & 0.045 & -0.042 \\
\hline Bicycle & 0.001 & -0.124 * & 0.035 & $0.350 *$ & 0.018 & 0.023 & $0.139 *$ & - & $0.192 *$ & 0.072 & $0.142 *$ & $0.143 *$ \\
\hline Income & 0.014 & -0.089 & -0.007 & 0.108 & $0.172 *$ & $-0.154^{*}$ & 0.041 & $0.192 *$ & - & $0.169 *$ & 0.114 & $0.221 *$ \\
\hline $\begin{array}{l}\text { Gender (reference } \\
\text { is Female) }\end{array}$ & $-0.136^{*}$ & 0.016 & -0.115 & 0.039 & 0.134 * & $-0.165^{*}$ & 0.045 & $0.142 *$ & 0.114 & $-0.135^{*}$ & - & -0.062 \\
\hline Children & -0.002 & 0.030 & 0.053 & -0.021 & 0.096 & -0.068 & -0.042 & $0.143 *$ & $0.221^{*}$ & $0.532 *$ & -0.062 & - \\
\hline
\end{tabular}

${ }^{*}$ Correlation is significant at the 0.05 level (2-tailed). 
Further characteristics of the journey which pointed to higher levels of commuter stress were, somewhat unsurprisingly, the distance between the home and the workplace, and the duration of the commute on a typical day.

Next, the characteristics of the commuters themselves were examined in relation to the level of commuter stress. No correlation was found between the amount of time an employee had been in their job, and commuter stress, even though it could be expected that a stressful commute would reduce the likelihood of staying with a particular employer (Wener and Evans 2004). However, except for the most extreme situations of commuter stress, it is likely that other factors, such as income and job satisfaction, for instance, are likely to have a greater influence on the intention to remain in a job. While income and age were not correlated with how stressful the commute was, gender (coded as a binary variable, which is an important limitation of this survey) was found to play a role. Women were more likely to report increased levels of commuter stress, with women also more likely to use public transport as part of their commute, and less likely than men to either drive or cycle. Women reporting higher commuter stress compared to men is consistent with earlier studies, although the specific dynamics which result in this gender difference have rarely been explored (Legrain et al. 2015).

Having to escort children on the way to work, e.g., dropping children off at school or kindergarten, was one of the variables associated with more stressful commutes. The interaction between gender and escorting duties in the production of commuter stress is worth examining in more detail, given the uneven data earlier studies have found on the gendered nature of chauffeuring children across different geographical contexts (Schwanen 2007; Scheiner 2016). In the case of Sofia, the added commuter stress women experience, and the stressfulness of escorting children as part of the commute, are likely to point to two separate sets of dynamics. This is because women in this sample were not any more likely than men to escort children on the way to and from work. This can be explained by men's greater likelihood of driving to work and driving to work being a good predictor of escorting children. The findings suggest that men's participation in child escorting duties mostly reflects men being more likely to have control of the family car, especially since two-car households remain relatively rare in Sofia (Vision for Sofia 2018; see Schwanen 2007 on men's travel mode influencing escorting likelihood). However, women's commutes were likely more stressful because of the range of other household and caregiving tasks they performed as part of their care responsibilities (Kwan and Kotsev 2014). In their narrative responses, women were more likely to report trip-chaining, for instance incorporating shopping, paying bills, and visiting relatives in need of care, as part of their journey to and from work. Importantly, workplace gender relations appear to have shaped answers here, since women in the 27 workplaces surveyed were more likely to be younger and in more junior posts; it can therefore be expected that they were less likely to have children and/or own a car.

These results are relatively consistent with previous studies; however, they present only a partial picture of the relations through which commuter stress is generated and experienced. In the next section, I examine further the role of workplaces in these processes, highlighting the nature of commuter stress as a collective as well as an individual phenomenon.

\subsection{Workplace Location and 'The Last Meter'}

In the survey, a distinction was made between workplace (employing organisation), and workplace location. This was necessary since, firstly, some of the companies surveyed had multiple offices in different locations in the city, and in addition, multiple companies surveyed shared the same location in office buildings and business parks. Thus, in examining the impact of the workplace on commuter stress, the analysis differentiates between the spatial characteristics of the workplace and its surroundings, and the organisational factors which determine aspects of the commute and its stressfulness (see next section). 
In examining the impact of the workplace location on commuter stress, only the five workplace locations for which at least thirty responses each were recorded were selected for this part of the analysis. Second, two locations of one employing organisation were excluded on the basis that a number of employees frequently worked across the two sites. A Kruskal-Wallis $\mathrm{H}$ test was used to analyse the differences between the mean levels of commuter stress reported by employees at the three remaining locations, and the differences were found to be statistically significant, $\mathrm{H}(2)=6.74, p=0.03$. Using a Mann-Whitney U test, a statistically significant difference was found between two of the research locations. The one associated with lower mean levels of commuter stress is located on the outskirts of the city, yet benefits from a range of public transport links and various facilities on-site and nearby, including diverse retail and food outlets. As respondents from the second location were significantly more likely to report heightened levels of commuter stress, it was examined in more detail, drawing on the qualitative data collected. This mixed-method approach draws on feminist approaches to transport and mobility research, which have highlighted the importance of specific, situated interactions between those on the move and the urban environment (Joelsson and Scholten 2019). For instance, research in this tradition has frequently highlighted the role of bus stops and their surroundings, or the experience of walking between the bus stop and home, in modulating what might otherwise be framed as a straightforward journey, defined by the use of a public transport mode (Collectiu Punt 6 2017).

The selected location, Top Business Building (pseudonym), is also on the outskirts of the city but is served by few and infrequent public transport connections. Unlike the first location, Top Business Building has no metro link and is reliant on bus services, which many respondents compared unfavourably to the underground rail in terms of comfort and reliability (see also Plyushteva 2019a). The location also has relatively few amenities such as retail, catering, or green space in the immediate vicinity. Despite this, and somewhat surprisingly, working at Top Business Building was not associated with a greater likelihood of driving. Analysis of the narrative responses submitted indicated a possible reason for this: employers at this location only covered part of the cost of parking at the site, leaving drivers to either shoulder the remaining expense, or to search for free street parking nearby. Because of having to park outside of the Top Business Building site, drivers were among the respondents who pointed to poor pedestrian infrastructure in the vicinity of the building as a source of commuter stress ( $9 \%$ of the 136 respondents based at Top Business Building). One respondent described the situation as " (.. ) missing sidewalks and ramps; we are stumbling along muddy paths in all kinds of weather, like mountain goats." The findings suggest that the heightened commuter stress associated with this location resulted from the dual pressure of having few options but to drive to and from work, while at the same time either having to pay for expensive parking or to face the uncertainties of parking further away.

This detailed analysis highlights the granular understanding of each stage of commuter journeys that is needed if the sources of commuter stress are to be adequately identified and addressed. Important differences in stressful experiences and their causes are missed as a result of the traditional approach of reducing the journey to the main transport mode (Olsson et al. 2013). 'Minor' parts of the journey, such as the last few steps to the front door, can play a key role in the socio-spatial relations within which commuter stress is generated. In addition, how these relations play out are often gendered. In the case of Top Business Building, this segment of the journey was especially likely to generate stressful experiences. This also meant that the frustration of navigating absent sidewalks and slippery surfaces directly preceded the start of the working day, with no time for it to dissipate. This finding should be of particular interest to employers concerned with the impact of commuter stress on productivity, well-being, and relations in the workplace. These inter-relations are discussed further in the next section. 


\subsection{The Role of the Employer and Workplace Relations}

This section examines the variation of commuter stress between the employees of different companies, as well as the nature and impact of any measures which employers implemented to improve (or regulate) commuting. Initially, a Kruskal-Wallis $\mathrm{H}$ test was used to test for differences in reported levels of stress between employees of the different companies. Here, the analysis included only those companies for which at least five responses were collected $(N=7)$. The test found that differences were not statistically significant $(\mathrm{H}(6)=5.06, p=0.536)$. These differences are explored in more detail in the rest of this section and incorporated in the ordinal logistic regression model presented in Table 3 and discussed below.

Table 3. Ordinal logistic regression model results for 'Level of commuter stress'.

\begin{tabular}{|c|c|c|c|c|}
\hline Variable & $\begin{array}{l}\text { Parameter } \\
\text { Estimate }\end{array}$ & $\begin{array}{l}\text { Standard } \\
\text { Error }\end{array}$ & $p$-Value & Odds-Ratio \\
\hline \multicolumn{5}{|l|}{ Intercept } \\
\hline 1 & -1.169 & 0.603 & 0.052 & 0.311 \\
\hline 2 & 0.400 & 0.587 & 0.496 & 1.492 \\
\hline 3 & 1.072 & 0.589 & 0.069 & 2.920 \\
\hline 4 & 4.184 & 0.650 & 0.000 & 65.639 \\
\hline \multicolumn{5}{|c|}{ Individual characteristics } \\
\hline \multicolumn{5}{|c|}{ Transport modes used } \\
\hline Private car & 1.606 & 0.282 & 0.000 & 4.980 \\
\hline Multimodal & 0.357 & 0.257 & 0.165 & 1.429 \\
\hline \multicolumn{5}{|l|}{ Trip duration } \\
\hline & 0.870 & 0.100 & 0.000 & 2.387 \\
\hline \multicolumn{5}{|c|}{ Gender (reference is Female) } \\
\hline & -0.831 & 0.235 & 0.000 & 0.436 \\
\hline \multicolumn{5}{|l|}{ Age } \\
\hline & -0.486 & 0.144 & 0.001 & 0.615 \\
\hline \multicolumn{5}{|c|}{ Escorting children } \\
\hline & 0.649 & 0.322 & 0.044 & 1.914 \\
\hline \multicolumn{5}{|c|}{ Workplace characteristics } \\
\hline \multicolumn{5}{|c|}{ Workplace location is TBB } \\
\hline & 0.124 & 0.241 & 0.606 & 1.132 \\
\hline \multicolumn{5}{|c|}{ Employing organisation } \\
\hline & 0.066 & 0.046 & 0.150 & 1.068 \\
\hline \multicolumn{5}{|c|}{ Employer measures } \\
\hline & -0.228 & 0.107 & 0.032 & 0.796 \\
\hline \multicolumn{5}{|c|}{ Measures seen as unfair } \\
\hline & 0.889 & 0.347 & 0.010 & 2.433 \\
\hline
\end{tabular}

A number of the workplaces covered by the study had implemented measures to facilitate the commutes of employees and/or shape commuting behaviours. Some of these interventions were part of organisational mobility plans, while others were described by respondents as ad-hoc policies. Organisational planning and/or policies around commuting could be motivated by human resource management concerns about staff reward and retention, financial concerns such as the high cost of car parking in office buildings and business parks, as well as a combination of the two. The most common provision reported by respondents was secure bicycle storage $(16 \%$ of respondents reported having 
access), followed by changing and showering facilities for cyclists (15\%), free or subsidised car parking $(15 \%)$, and free or subsidised public transport travelcards $(12 \%)$. The level of support for commuters, ranked on a 5-point Likert scale by respondents, varied significantly between companies $(\mathrm{H}(3)=12.60, p=0.01)$. Most importantly, lower levels of commuter stress were reported by the employees of those companies which were seen to put substantial resource into policies for making commuting easier, more affordable, and less stressful (Table 3).

However, these interventions could also become a source of frustration and even resentment, as indicated by the narrative responses provided. Several respondents complained about unequal treatment, such as privileging drivers by subsidising parking but not providing equivalent assistance for users of other modes. Other examples included providing company transport which served some routes but not others, and not attending to the specific needs of employees who worked with other time zones and thus had to travel when public transport was scarce. One respondent summarised these divisions thus: "The company makes very many provisions for the commutes of its special employees, and offers hardly anything at all for us ordinary employees." This was supported by the finding, obtained using a Spearman's rho correlation, that higher-income employees were more likely to report receiving company support related to improving commuting affordability and convenience $\left(r_{s}=0.183, p=0.02, N=189\right)$. These results highlighted the complex links between commuter stress and workplace relations. On one hand, employer mobility measures were undeniably beneficial for individual commuters, and thus could be seen as beneficial to relations in the workplace, if the impact of commuter stress is construed simply as a matter of aggregation from individual stressful journeys, to prevailing sentiments among the workplace community. However, in practice, individual commuters' stress was also shaped by the support others were (perceived to be) receiving from the employing organization. These indirect impacts on commuter stress are in line with recent insights from research on community well-being (Atkinson et al. 2020). As highlighted also by the narrative responses analysed, workplace commuter stress is a matter of a complex dynamic that goes beyond simple aggregation. The perceived fairness and transparency in the implementation of employer mobility plans could clearly reshape their impact on how employees experienced stress, and potentially how they related to each other. While these initial results present an outline of some of the dynamics, further qualitative research is needed to explore how these linkages are understood and acted upon in practice.

The final stage of the analysis included incorporating the identified individual and organisational variables of interest in ordinal logistic regression, the results of which are presented in Table 3. The results suggest that individual characteristics, and in particular travel mode, can be strong predictors of commuter stress. While this finding for driving is consistent with previous literature, the role of multimodal journeys in increasing the likelihood of experiencing commuter stress is an important finding which warrants further examination. The results on the role of workplace characteristics, while exploratory in nature, suggest that further attention should be given to how workplace location, employer practices, and workplace relations, modulate the experience of commuter stress. The results suggest that employees working at the same location for different organisations may well experience different levels of commuter stress, and similarly, working at one of several locations of the same employer can lead to different levels of commuter stress. A particularly interesting finding is that employees who felt that the support provided by their employing organization to commuters was unequal or unfair (e.g., in terms of access to subsidized car parking or public transport travelcards), were also more likely to report higher levels of commuter stress. This indicated that employer mobility plans are likely to have a wider impact on stress and well-being, and on social relations in the workplace than previously thought.

It is also important to contextualize these findings on the responsibility of the employer with the strong feelings many respondents expressed regarding the role of local government. While only $28.0 \%$ of respondents were fully satisfied with the amount of effort their 
employer invested into improving the experience of commuting, the comments respondents volunteered suggested an even lower degree of satisfaction with the work of the local municipal and transport authorities. The majority of narrative respondents analysed highlighted that the ability of employers to reduce commuter stress is constrained by the reluctance of local government agencies to act decisively to reduce traffic congestion, air pollution, road accidents, and unreliable public transport services. However, it is also worth noting that there was little agreement among respondents, both within and across each of the studied workplace locations, on the steps which would alleviate such problems (e.g., restrict car traffic vs. add lanes and parking facilities). By contrast, the 'wish-list' respondents provided in response to the question of what else their employer could do to improve commuting, was much more homogenous. While these results cannot be interpreted as a definitive list of effective employer mobility measures, employee support for free or subsidised public transport travelcards was the most widespread (11\% of respondents), followed by improved cycle storage and shower facilities, $(7 \%)$. Future research could explore the prevalence of commuter stress among employees, and their evaluation of workplace social relations, prior to, and after, the implementation of such measures.

\section{Discussion and Conclusions}

The discussion above is inevitably partial and deliberately highly contextual in its approach to commuter stress and the workplace. Within these constraints, the paper aimed to make three contributions to understanding the workplace-commuter stress relationship. First, understanding the impact of the spatial and organisational characteristics of the workplace on commuter stress is an engagement with the sequencing and interconnectedness of different daily activities, an engagement which is rarely undertaken in well-being studies (Schwanen and Wang 2014). Second, the paper contributes to the much-discussed, but rarely realised, need to de-centre the individual, rational, intentional subject who remains dominant in transport and mobility research (Manderscheid 2013). Finally, the paper draws on the concept of community well-being focusing on the workplace rather than residential communities, and using it to examine the linkages between individual commuter stress, and collective well-being in the workplace. With these aims in mind, the discussion highlighted the importance of including the workplace and workplace relations in analyses of commuter stress and demonstrated the value of combining qualitative and quantitative methods in doing so. In the course of the analysis, the paper drew attention to frequently overlooked aspects of the commute, such as multimodality, micro-level characteristics of the urban and work environment, and the interplay of gender relations and presence of children in the access to private cars of men and women within the same household. In addition, the paper provided a nuanced account of how workplace mobility plans and strategies, often focused on environmental effects, have broader implications for social relations and well-being.

The workplace is part of the specific social and spatial contexts in which commuter stress is generated, amplified, and dampened (what Bissell 2014, calls the "radically contingent and irreducibly specific nature of commuter stress"). The present paper is an initial effort to conceptualise, and empirically investigate, the diverse interconnections between individuals' commutes, individual and shared experiences of commuter stress, and the relations of the workplace. From a practical perspective, it provides evidence to encourage employers to give greater attention to alleviating commuter stress. For example, efforts to monitor and address commuter stress could be more prominently incorporated in workplace mobility plans. This also reflects the need to counter the individual responsibilities of stressed commuters, which reflects the persistent idea that everyday mobility behaviours are the result of utility-maximising individual decisions (Schwanen and Atkinson 2015; Scholten and Joelsson 2019). Future research on commuter stress and workplace relations will further elaborate on the link between commuter stress, the workplace, and community well-being. 
Funding: This research was funded by postdoctoral fellowship funded by the European Union Horizon 2020 programme under Marie Skłodowska-Curie grant agreement number 703047, with additional support from Sofia Municipality, Sofia, Bulgaria.

Institutional Review Board Statement: The study was conducted according to the guidelines of the Declaration of Helsinki, and approved by the Ethics Committee of the Vrije Universiteit Brussel (ECHW_084, 24 April 2017).

Informed Consent Statement: Informed consent was obtained from all subjects involved in the study.

Data Availability Statement: The data presented in this study are available on request from the corresponding author.

Conflicts of Interest: The author declares no conflict of interest.

\section{References}

Abou-Zeid, Maya, and Moshe Ben-Akiva. 2011. The Effect of Social Comparisons on Commute Well-Being. Transportation Research Part A: Policy and Practice 45: 345-61. [CrossRef]

Atkinson, Sarah, Anne-Marie Bagnall, Rhiannon Corcoran, Jane South, and Sarah Curtis. 2020. Being Well Together: Individual Subjective and Community Wellbeing. Journal of Happiness Studies 21: 1903-21. [CrossRef]

Barnfield, Andrew. 2017. Experiencing Post-Socialism: Running and Urban Space in Sofia, Bulgaria. European Urban and Regional Studies 24: 368-80. [CrossRef]

Bissell, David. 2010. Passenger Mobilities: Affective Atmospheres and the Sociality of Public Transport. Environment and Planning D 28: 270-89. [CrossRef]

Bissell, David. 2014. Encountering Stressed Bodies: Slow Creep Transformations and Tipping Points of Commuting Mobilities. Geoforum 51: 191-201. [CrossRef]

Chatterjee, Kiron, Ben Clark, Adam Martin, and Adrian Davis. 2017. The Commuting and Wellbeing Study: Understanding the Impact of Commuting on People's Lives. Bristol: UWE Bristol.

Collectiu Punt 6. 2017. Nocturnas: The Everyday Life of Women Nightshift Workers in the Barcelona Metropolitan Area. Barcelona: Collectiu Punt 6.

Cox, Tom, Jonathan Houdmont, and Amanda Griffiths. 2006. Rail Passenger Crowding, Stress, Health and Safety in Britain. Transportation Research Part A: Policy and Practice 40: 244-58. [CrossRef]

De Vos, Jonas, Tim Schwanen, Veronique Van Acker, and Frank Witlox. 2013. Travel and Subjective Well-Being: A Focus on Findings, Methods and Future Research Needs. Transport Reviews 33: 421-42. [CrossRef]

Ettema, Dick. 2010. Out-of-Home Activities, Daily Travel, and Subjective Well-Being. Transportation Research Part A: Policy and Practice 44: 723-32. [CrossRef]

Gatersleben, B., and D. Uzzell. 2007. Affective Appraisals of the Daily Commute: Comparing Perceptions of Drivers, Cyclists, Walkers, and Users of Public Transport. Environment and Behavior 39: 416-31. [CrossRef]

Gilow, Marie. 2020. "It's Work, Physically and Logistically": Analyzing the Daily Mobility of Employed Mothers as Domestic Mobility Work. Journal of Transport Geography 85: 102693. [CrossRef]

Hennessy, Dwight A. 2008. The Impact of Commuter Stress on Workplace Aggression. Journal of Applied Social Psychology 38: 2315-35. [CrossRef]

Hirt, Sonia. 2007. Suburbanizing Sofia: Characteristics of Post-Socialist Peri-Urban Change. Urban Geography 28: 755-80. [CrossRef]

Joelsson, Tanja, and Christina Lindkvist Scholten. 2019. The Political in Transport and Mobility: Towards a Feminist Analysis of Everyday Mobility and Transport Planning. In Integrating Gender into Transport Planning. Edited by Christina Lindkvist Scholten and Tanja Joelsson. Cham: Springer, pp. 1-22. [CrossRef]

Koslowsky, Meni, Avraham N. Kluger, and Mordechai Reich. 1995. Commuting Stress: Causes, Effects, and Methods of Coping. New York: Springer Science \& Business Media. [CrossRef]

Kwan, Mei-Po, and Alexander Kotsev. 2014. Gender Differences in Commute Time and Accessibility in Sofia, Bulgaria: A Study Using 3D Geovisualisation. The Geographical Journal 181: 83-96. [CrossRef]

LaJeunesse, Seth, and Daniel A. Rodríguez. 2012. Mindfulness, Time Affluence, and Journey-Based Affect: Exploring Relationships. Transportation Research Part F: Traffic Psychology and Behaviour 15: 196-205. [CrossRef]

Legrain, Alexander, Naveen Eluru, and Ahmed M. El-Geneidy. 2015. Am Stressed, Must Travel: The Relationship between Mode Choice and Commuting Stress. Transportation Research Part F: Traffic Psychology and Behaviour 34: 141-51. [CrossRef]

Manderscheid, Katharina. 2013. Criticising the Solitary Mobile Subject: Researching Relational Mobilities and Reflecting on Mobile Methods. Mobilities 9: 188-219. [CrossRef]

Morris, Eric A., and Erick Guerra. 2015. Mood and Mode: Does How We Travel Affect How We Feel? Transportation 42: 25-43. [CrossRef] 
National Statistics Institute. 2018. Population by Regions, Areas, Registered Address and Gender. Sofia: National Statistics Institute. Available online: http://www.nsi.bg/bg/content/2975/\%D0\%BD \%D0\%B0\%D1\%81\%D0\%B5\%D0\%BB\%D0\%B5\%D0\%BD\% D0\%B8\%D0\%B5-\%D0\%BF\%D0\%BE-\%D0\%BE\%D0\%B1\%D0\%BB \%D0\%B0\%D1\%81\%D1\%82\%D0\%B8-\%D0\%BE\%D0\%B1\%D1

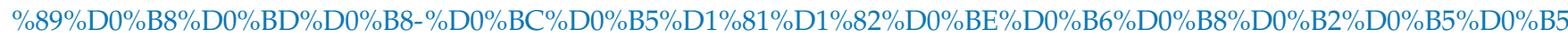
$\% \mathrm{D} 0 \% \mathrm{BD} \% \mathrm{D} 0 \% \mathrm{~B} 5-\% \mathrm{D} 0 \% \mathrm{~B} 8-\% \mathrm{D} 0 \% \mathrm{BF} \% \mathrm{D} 0 \% \mathrm{BE} \% \mathrm{D} 0 \% \mathrm{BB}$ (accessed on 31 May 2021).

Olsson, Lars E., Tommy Gärling, Dick Ettema, Margareta Friman, and Satoshi Fujii. 2013. Happiness and Satisfaction with Work Commute. Social Indicators Research 111: 255-63. [CrossRef] [PubMed]

Plyushteva, Anna. 2019a. Predictability and Propinquity on the Sofia Metro: Everyday Metro Journeys and Long-Term Relations of Transport Infrastructuring. In Post-Socialist Urban Infrastructures. Edited by Tauri Tuvikene, Wladimir Sgibnev and Carola Neugebauer. London: Routledge.

Plyushteva, Anna. 2019b. Commutes and Co-Workers: Complicating Individual Journeys through Workplace Relations. Built Environment 45: 603-20. [CrossRef]

Scheiner, Joachim. 2016. School Trips in Germany: Gendered Escorting Practices. Transportation Research Part A: Policy and Practice 94 76-92. [CrossRef]

Scholten, Cristina Lindkvist, and Tania Joelsson, eds. 2019. Integrating gender into transport planning: From one to many tracks. Cham, Switzerland: Springer.

Schwanen, Tim, and Donggen Wang. 2014. Well-Being, Context, and Everyday Activities in Space and Time. Annals of the Association of American Geographers 104: 833-51. [CrossRef]

Schwanen, Tim, and Sarah Atkinson. 2015. Geographies of Wellbeing: An Introduction. The Geographical Journal 181: 98-101. [CrossRef]

Schwanen, Tim, and Tom de Jong. 2008. Exploring the Juggling of Responsibilities with Space-Time Accessibility Analysis. Urban Geography 29: 556-80. [CrossRef]

Schwanen, Tim. 2007. Gender Differences in Chauffeuring Children among Dual-Earner Families. The Professional Geographer 59: 447-62. [CrossRef]

Singleton, Patrick A., Jonas De Vos, Eva Heinen, and Baiba Pudāne. 2020. Potential Health and Well-Being Implications of Autonomous Vehicles. In Advances in Transport Policy and Planning. Amsterdam: Elsevier, vol. 5, pp. 163-90. [CrossRef]

Sposato, Robert G., Kathrin Röderer, and Renate Cervinka. 2012. The Influence of Control and Related Variables on Commuting Stress. Transportation Research Part F: Traffic Psychology and Behaviour 15: 581-87. [CrossRef]

Stanilov, Kiril, and Sonia Hirt. 2014. Sprawling Sofia: Postsocialist Suburban Growth in the Bulgarian Capital. In Confronting Suburbanization: Urban Decentralization in Postsocialist Central and Eastern Europe. Edited by Kiril Stanilov and Ludek Sykora. Chichester: Wiley \& Sons, pp. 163-91.

Vision for Sofia. 2018. Step 2: Report on the Theme of Transport; Sofia: Vision fo Sofia. Available online: www.vizia.sofia.bg (accessed on 31 May 2021).

Wener, Richard E., and Gary W. Evans. 2011. Comparing Stress of Car and Train Commuters. Transportation Research Part F: Traffic Psychology and Behaviour 14: 111-16. [CrossRef]

Wener, Richard, and Gary Evans. 2004. The Impact of Mode and Mode Transfer on Commuter Stress: The Montclair Connection: Final Report. Submitted by Richard E. Wener and Gary W. Evans. FHWA-NJ-2004-005. Trenton: New Jersey Department of Transportation or the Federal Highway Administration. Available online: http:/ / dspace.njstatelib.org/xmlui/handle/10929/23979 (accessed on 31 May 2021). 